\title{
Knowledge exchange and the Third Mission of universities
}

\section{Introduction: the Triple Helix and the Third Mission - Schumpeter revisited}

\section{Girma Zawdie}

Girma Zawdie, the Co-Editor of this special issue, is with the David Livingstone Centre for Sustainability, Department of Civil Engineering, University of Strathclyde, Graham Hills Building, 50 Richmond Street, Glasgow G1 1XN, UK. E-mail: g.zawdie@strath.ac.uk.

Joseph Schumpeter (1883-1950) is well known as an economist, among other things, for his seminal contribution explaining long-term economic growth in terms of innovation and technological progress. $\mathrm{He}$ identified innovation at the heart of upswings in the so-called 'Kondratiev waves' that profile socioeconomic development trends over long periods. He saw innovation as a dynamic process of "creative destruction' in which new orders arise with the obliteration of the old. This process he attributed to the entrepreneur - the innovator who, in the Schumpeterian paradigm, would in effect count as a history maker. For all its significance as a landmark in the literature of innovation and economic development, Schumpeter's contribution falls short of providing a theory of innovation. However, he has left behind a long-standing tradition of innovation studies to grapple with this shortfall. The quest continues in the form of innovation systems and evolutionary theory, in which the Triple Helix features as a strand.

There is a Schumpeterian antecedent to the theme of this special issue, which portrays entrepreneurial universities as the powerhouse of innovation. The issue comprises contributions selected from the proceedings of the 7th Triple Helix International Conference on the relationship between universities, industry and government. The conference, hosted by the University of Strathclyde in Glasgow on 17-19 June 2009, focused on 'The role of the Triple Helix in the global agenda for innovation, competitiveness and sustainable development' and addressed the evolving role of universities as centres of knowledge production through teaching and research. How, for example, are universities positioned in relation to industry and government to impact on the economy, society and the environment and to address the contemporary global challenges of poverty, unemployment, environmental degradation and climate change? In other words, to what extent have universities managed to shed their long-standing 'ivory tower' image and engage in the pursuit of the Third Mission?

Universities in many countries have come a long way from their traditional ivory tower stance to assume an increasingly dynamic entrepreneurial role by strategically connecting to key players in the wider economy. This development has led to the emergence of two interdependent concepts - the Triple Helix and the Third Mission. Together, these concepts define the role universities are expected to play in the process of innovation and sustainable development. Governments would, as a matter of policy, like to ensure by means of funding mechanisms that universities are positively 
engaged in regional and national development through the pursuit of research and development, leading to innovation, knowledge exchange and technology transfer. The Triple Helix is, strictly speaking, a response to this policy concern. The implicit assumption here is that the Third Mission of universities can be effectively and sustainably pursued in the context of the Triple Helix model. Conceptually, this locates the Third Mission argument within the overarching framework of innovation systems and sustainable development.

The Third Mission differs from the other two missions of universities insofar as it makes them not merely passive agents of knowledge production, but rather power-houses of innovation, and hence strategic agents of sustainable development. Teaching constitutes the first mission of universities. It took, as Etzkowitz (1998) recounts, the 'first academic revolution' during the 19th century for research to emerge as the 'second mission' of universities. Emergence of the second mission occurred apparently in the face of heavy resistance stemming from the presumption that engagement in research might adversely affect the quality and quantity of teaching. In the event, far from being competitive, teaching and research were found to be synergistic and mutually beneficial.

However, engagement in teaching and research does not ipso facto warrant commitment to development as long as those activities are not effectively integrated into the socio-economic and cultural milieux that bear on the operation of universities. Indeed, where universities are least geared to responding to the needs of the wider economy and society, as is the case particularly in many developing countries, they exist as bastions of elitism: hence the case for a 'second academic revolution' to usher in entrepreneurial universities that are firmly engaged in the pursuit of the Third Mission.

The Third Mission is not only about the university impacting on the wider economy and society through the generation of research-based innovation. It is also about the university itself experiencing impacts through, for example, changes in funding structures, the establishment of technology transfer offices (TTOs) and legislation for the commercialization of research and intellectual property rights (IPRs). The commercialization of research through TTOs, spin-off enterprises, business incubators, science parks and the institution of IPR mean that universities can pursue entrepreneurial activities with the objective of improving regional or national economic performance as well as their own financial advantages.

The Third Mission should not, however, be construed as an add-on to the traditional university activities of teaching and research. It is essentially the product of institutional and cultural change associated with the evolution of the university system underpinned by innovative and entrepreneurial values. It is also at the same time a response to the recognition that scientific and technological knowledge is crucial to sustainable regional and national development and that the university is, after all, a cost-effective inventor and transfer agent of both knowledge and technology (Etzkowitz et al, 2000). Thus, the Third Mission of universities would see the teaching and research effort of universities translating into economic development through various forms of technology transfer that support the modernization of low-tech and mid-tech firms.

But this cultural shift towards the 'entrepreneurial university' position, however important for the pursuit of the Third Mission, is not without challenges. For instance, some would view the entrepreneurial paradigm as a threat to the traditional integrity of the university and would argue that it should be firmly resisted (Pelikan, 1992; Brooks, 1994), or else relegated to a special class of institutions of higher education, lest the pursuit of narrow pecuniary objectives should deprive the university of its role as an independent critic of society (Krimsky, 1991). Moreover, some companies, which see new firms emerging from academia as potential competitive threats, would argue that universities should confine themselves to the narrow traditional and often ad hoc university-industry relationships, such as consultation (Etzkowitz, 1996; Etzkowitz et al, 2000).

For all this, there is, as is apparent from the various contributions to this special issue, a growing policy recognition in both developed and developing countries that the future of universities lies in the development of the Third Mission underpinned by entrepreneurial culture. Development of the Third Mission, however, begs the question of what roles industry and government would need to assume as key players in the wider economy and society to complement the emergence of entrepreneurial universities with a Third Mission and the generation of knowledge and innovation on a sustainable basis. Thus the Third Mission brings in its train the Triple Helix system of university-industrygovernment interaction, with universities aiming to cultivate entrepreneurial culture and commercialize research; industry aiming to participate in research and in the sharing of knowledge and best practice; and government aiming to promote investment in higher education and research capacity building.

The Triple Helix concept was first proposed by Etzkowitz and Leydesdorff $(1995 ; 2000)$ in the context of the evolutionary theory of innovation (Nelson and Winter, 1977; 1982) to explain the systemic nature of the interaction between universities (engaged in 
knowledge generation and transfer), industry (engaged in the application of knowledge) and government (engaged in the provision of the requisite policy framework for knowledge circulation to thrive). The Triple Helix model thus represented an attempt to engage in a much wider discussion about the national innovation system (NIS) concept initiated by Freeman (1987) and Lundvall (1988). In the context of the Triple Helix, evolutionary theory conceptualizes the evolving relationship between the three institutional spheres culminating in the formation of a hybrid system in which the university ultimately will have acquired entrepreneurial character, enhanced its innovation performance and engaged in the pursuit of the Third Mission agenda (Etzkowitz and Leydesdorff, 2000). The blurring of institutional boundaries in the evolutionary process would make way for innovation and cross-sectoral knowledge circulation or knowledge exchange to occur. This is akin to the networking principle underlying the NIS.

The NIS, unlike the Triple Helix, however, came into use mainly as a result of the policy objective of safeguarding a substantial proportion of the benefits due to the innovation process from being externalized and lost to the national economy through globalization. Thus it can be argued that, whereas the NIS provides a macro perspective of the innovation process, the Triple Helix provides micro and meso perspectives. Indeed, the Triple Helix was introduced into the discussion of innovation systems, presumably on the back of the Third Mission argument, not as a critique of or a substitute for the NIS, but as a perspective for operationalizing the NIS by promoting cooperative interaction between the knowledge (university), production (industry) and public (government) sectors, so that knowledge circulation across those sectors would pave the way for an innovation culture to be firmly rooted in the economy. The knowledge sector is expected to take the lead in this respect through the Third Mission of universities. Moreover, whereas the NIS would seek to retain the benefits of globalizing knowledge within specified geographical boundaries, the Triple Helix underpins the study of innovation systems at various levels of institutional and functional categories, thus enriching the conceptual and empirical dimensions of innovation as a systemic phenomenon, and improving the effectiveness of innovation policies at regional and national levels.

What is apparent from the above discussion is that the ascendancy of the knowledge economy has brought to the fore the entrepreneurial role of the university and its impact on the wider economy and society through the Third Mission exercised within the Triple Helix framework. There are, however, questions about the conceptual and empirical aspects of the Third Mission, the university's position in the Triple Helix system, and the effectiveness of the Triple Helix system itself in promoting innovation, industrial competitiveness and sustainable development. The seven papers included in this special issue explore the conceptual and empirical ramifications of the link between the Third Mission and the Triple Helix system of innovation in the light of different national and policy circumstances. The following points can be teased out from the contributions.

First, given the significance of the Third Mission, the question arises as to how best its impact can be maximized through changes in public policy and institutional design. Nelles and Vorley address this question by pointing out the need to understand the factors that underpin the Third Mission of contemporary universities. This leads them to introduce the concept of 'entrepreneurial architecture' as a first step in developing a theoretical understanding of entrepreneurialism and the Third Mission within contemporary universities. The authors therefore call for more research to bridge the knowledge gap between the abstract conceptualizations of the contemporary university and the empirical studies of the Third Mission.

Second, what can be said about the take-up of the Triple Helix as a framework for innovation strategy, or is it dispensable? This varies across countries depending on the policy regime and the underlying economic, social, cultural and political circumstances. Based on relevant policy experience in Greece, Stathis Arapostathis discusses the influence of politics on the relationship between academia, industry and government. He explains the emergence of the Triple Helix in Greece as a process that happened concurrently with changes in political, economic and cultural conditions. The shift in political ground from the left towards the centre, the adoption of privatization as an instrument of policy, and the establishment of a modern business culture are considered to be the major factors that prompted universities to forge links with the corporate world. Moreover, the Triple Helix was found to be a convenient response to the pressure placed on the country by its EU membership to align its industrial, scientific and innovation system with the other EU members. However, for all Greece's flirtation with market liberalism, Arapostathis argues that the persistence of the interventionist instinct of the government has squeezed the private sector in the Triple Helix structure, while research and development and the task of knowledge generation have remained concentrated in the government sector and in statefunded universities. This is akin to what Etzkowitz 
and Leydesdorff (2000) refer to as the etatist (statedominated) model of the Triple Helix - an arrangement which, however politically expedient, does not allow exploitation of the full innovation potential of the economy.

However, the interventionist role of government does not necessarily have a limiting effect on the evolution of Triple Helix, as the Greek case appears to suggest. Yuwawutto et al show the positive role of policy intervention in developing the Triple Helix relationship as a strategy for the development of small and medium-sized enterprises (SMEs) in Thailand. Here, the government created an intermediary organization dedicated to the service of identifying the needs of SMEs and accessing on their behalf relevant knowledge and technology from universities and other knowledge sources, thus matching the knowledge/technology demand and supply matrix for SMEs. In developing countries, where there are few or no systemic interactions between academia, industry and government, intermediaries could play a crucial role in promoting a culture of trust and social capital development through network building, thereby enabling SMEs to have access to various sources of knowledge, technology and market support, and universities to pursue the Third Mission agenda.

Third, what constitutes the dynamics in the Triple Helix system? There is indeed more to the Triple Helix than the trilateral institutional links. Fernández-Esquinas et al show that, as the Triple Helix system evolves, the underlying dynamics will precipitate a complex set of networks and a whole range of actors engaged in the provision of knowledge to underpin innovation at the level of the firm. This means that the effectiveness of the Triple Helix as a basis for innovation capacity building and as a framework for sound regional development will depend on the choices firms make regarding specific pathways for collaboration. Based on their empirical study involving a survey of 737 firms from a region in southern Spain, the authors show that innovative firms rely on business networks, clients and providers of knowledge services in addition to universities and governments. Firms that adopt an open collaboration strategy are, therefore, considered to have greater capacity to recombine different knowledge sources and adapt them to their innovation processes.

Fourth, what are the critical factors that prompt effective knowledge transfer from academia to industry? Villanueva-Felez et al put emphasis on the characteristics of individual researchers $-\mathrm{a}$ factor which they note is, however, seldom considered. Based on a survey of experiences in the field of nanotechnology in Spain and The Netherlands, the authors show how the ties between individuals and the interdisciplinary nature of the research and its pervasiveness affect the diversity of knowledge transfer activities. In a highly interdisciplinary and pervasive field like nanotechnology, they argue, the link between a single academic researcher and a single firm would involve several transfer channels; and firms would be willing to invest in such resources to tap into the knowledge base of academic researchers. This choice exercised at the level of the firm constitutes a demand-side argument that could be integrated into the Triple Helix system to enhance the effectiveness of the Third Mission of universities.

Fifth, how best can research be organized to make the innovation process work? Gray and Sundstrom suggest that Triple Helix researchers would be more effective in explaining the dynamics underlying the innovation process through active engagement in cooperative research that, in their view, would bridge the gap between the Triple Helix and the 'science of team science'. The view that team-based partnerships and collaboration would significantly benefit the innovation process constitutes a supply-side approach to the way in which Triple Helix research could be designed to respond effectively to the needs of industry.

Sixth, how best can the demand-side and supply-side approaches discussed above be brought together to foster innovation in the context of the Triple Helix and the Third Mission? Lowegren and Bengtsson discuss the case of university spin-offs (USOs) in Sweden which are, in effect, the interface of university-industry relationships. But how effective are these USOs as such an interface? The authors find that USOs generally tend to be active in simpler business forms, like consultancy services. They also find evidence of USOs being research active and also active in the transfer of knowledge and technology through the selling of licences and IPRs to other companies.

The growing commitment of contemporary universities to the Third Mission as the interface between higher education and industry is also highlighted by Riviezzo and Napolitano with reference to the experience of universities in Italy. Italian universities have moved towards entrepreneurial activities in recent years, making a significant cultural departure from the past. This cultural shift, which has engaged them in the valorisation and 'exploitation' of the scientific knowledge they produce, was influenced by both internal and external factors. The external factors relate to the overarching legal, economic and policy environments that impinge on the national innovation system and consequently on the rate and direction of knowledge production and transfer. Among the internal factors that have prompted the commitment to the Third Mission, the creation of specialized 
organizational units (TTOs) to promote and manage the industrial exploitation of scientific research is considered to have been crucial.

It is apparent from the above discussion that the various contributions to this special issue have sought to address the issues of the Triple Helix, the Third Mission and technology transfer and knowledge exchange from different perspectives and in the light of different national circumstances. The contributions are helpful in advancing our understanding of the innovation problem that has exercised minds since Schumpeter. The Triple Helix idea of explaining innovation as a systemic category has generated growing intellectual and policy appeal over the last couple of decades, particularly as a basis for capacity building and as a framework for setting in context the Third Mission of universities. It has also exposed the complex nature of the innovation system, calling for more research to shed light on the theoretical adequacy, empirical validity and policy usefulness of the Triple Helix framework within which the entrepreneurial transformation of universities and the Third Mission are to occur.

\section{References}

Brooks, H. (1994), 'Research universities and the social contract for science,' in Bramscomb, L., ed, Empowering Technology, MIT Press, Cambridge, MA, pp 202-234.
Etzkowitz, H. (1996), 'Conflicts of interest and commitment in academic science in the United States', Minerva, Vol 34, pp 259-277.

Etzkowitz, H. (1998), 'The norms of entrepreneurial science: cognitive effects of the new university-industry linkages', Research Policy, Vol 27, pp 823-833.

Etzkowitz, H., and Leydesdorff, L. (1995), 'The Triple Helix university-industry-government relations: a laboratory for knowledge-based economic development', EEAST Review, Vol 14, pp 14-19.

Etzkowitz, H., and Leydesdorff, L. (2000), 'The dynamics of innovation: from national systems and "Mode 2" to a Triple Helix of university-industry-government relations', Research Policy, Vol 29, pp 109-123.

Etzkowitz, H., Webster, A., Gebhardt, C., and Terra, B.R.C (2000), 'The future of the university and the university of the future: evolution of ivory tower to entrepreneurial paradigm', Research Policy, Vol 29, pp 313-330.

Freeman, C. (1987), Technology Policy and Economic Performance: Lessons from Japan, Pinter, London.

Krimsky, S. (1991), 'Academic-corporate ties in biotechnology: a quantitative study', Science, Technology and Human Values, Vol 16, pp 275-287.

Lundvall, B.A. (1988), 'Innovation as an interactive process: from user-producer interaction to the national system of innovation', in Dosi, G., Freeman, C., Nelson, R., Silverberg, G., and Soete, L., eds, Technical Change and Economic Theory, Pinter, London, pp 349-369.

Nelson, R.R., and Winter, S.G. (1977), 'In search of useful theory of innovation', Research Policy, Vol 6, pp 35-76.

Nelson, R.R., and Winter, S.G. (1982), An Evolutionary Theory of Economic Change, Harvard University Press, Cambridge, MA.

Pelikan, J. (1992), The Idea of the University: a Re-examination, Yale University Press, New Haven, CT. 